\title{
«La sangre no puede mentir». Entre una concepción genético-estratégica del territorio y una manera relacional de ver el mundo*
}

\section{Laura Volpi}

https://orcid.org/0000-0002-7672-3200.

Univesidad Estatal de Milán (UNIMI)

laura.volpi@unimi.it

\section{RESUMEN}

Los nativos kichwa (selva alta peruana) están enfrentando un conflicto territorial debido al establecimiento de un Área de Conservación Regional en sus tierras de origen. Para cuestionar la legitimidad de sus reivindicaciones territoriales, el gobierno regional está planteando la hipótesis de una migración andina kichwa. Por otro lado, varios mediadores culturales esperan ayudar a este pueblo utilizando algunas investigaciones biomoleculares (Sandoval et al., 2016; Barbieri et al., 2017) que certifiquen «cientificamente» su relación ancestral con las tierras reclamadas. Este artículo busca examinar los malentendidos existentes sobre los conceptos de «ascendencia» y «territorio», cuyo significado, en el ámbito indígena, supera los límites impuestos por la jurisdicción nacional y la terminología jurídica. De hecho, a pesar de haber asimilado un discurso genético-ancestral, varios líderes indígenas hoy lo van remodelando a la luz de una concepción nativa del territorio, entendida como una compleja red de relaciones, presentes y activas, entre los seres humanos vivos y los ancestros.

Palabras clave: ancestralidad, territorio, génetica, modelo relacional, kichwa.

Este estudio fue financiado por el Departamento de Filosofía Piero Martinetti, de la Universidad de Milán, dentro del proyecto Departamentos de Excelencia 2018-2022, concedido por el Ministerio de Educación, Universidad e Investigación (MIUR). 


\section{«Blood cannot lie». Between a genetic-strategic conception of territory and a relational way of seeing the world}

ABSTRACT

Kichwa indigenous people of the Peruvian Amazon Forest are facing a territorial conflict due to the establishment of a Regional Conservation Area on their homelands. In order to question the legitimacy of native claims, the Regional Government puts forward the hypothesis of the Andean kichwa migration. On the other hand, several cultural mediators hope to help this native people, using some biomolecular investigations (Sandoval et al., 2016; Barbieri et al., 2017) that «scientifically» certify its ancestral relationship with the surrounding territories. This article wants to examine the existing misunderstandings about the concepts of «ancestry» and "territory» whose meaning, in the native sphere, overcomes limits imposed by national jurisdiction and legal terminology. Despite having assimilated an ancestral-genetic discourse, several indigenous leaders reshape it in light of a native conception of territory, perceived as a complex network of present and active relationships between living people and ancestors.

Keywords: ancestry, territory, genetics, relational model, Kichwa. 
Habia un análisis de la sangre en aquellos tiempos, ¿no? Para ver, de verdad si somos de los chankas y pokras [...]. Y total, que el resultado del análisis de la sangre dice que no somos de los chankas: somos amazonenses. Somos pueblos indigenas. [...] Hubo un gran debate, con profesionales. Y ellos pidieron a los mestizos, porque nos habían contado esa historia. Hasta a la escuela nos habian enseñado esto, que somos raza chanka. Nosotros hemos creído, pues [...]. Hubo un poco de resistencia. Unos apus decían: ¿¿Por qué solo ahora [los cientificos] vienen y nos dicen esto?» [...]. Pero

la sangre no puede mentir. O bueno... así dicen, ¿no? No puede mentir la sangre: si somos de raza chanka, la sangre debe ser igual, ¿no? Yo, por ejemplo, tengo un hijo y mi sangre es la suya. La sangre no puede cambiarl.

En 2012, en la selva alta de San Martín, tuvo lugar un encuentro bastante inusual: un equipo de genetistas se puso en contacto con algunos líderes indígenas kichwa para definir los métodos de realización de una investigación biomolecular, que habría involucrado a varios clanes familiares nativos. Cuatro años más tarde, como se puede observar de la entrevista aquí citada, los indígenas de San Martín recibieron la noticia de la refutación de su propio mito de origen, es decir, de la historia que los ve como descendientes de los antiguos guerreros chankas y pokras.

Según esa narración mítica (contada por los mestizos de la zona y difundida en todo el Perú) este valiente y belicoso pueblo, originario del departamento de Huancavelica, en el año 1438 emprendió un largo viaje para escapar de la expansión del Tawantinsuyu. Liderados por el famoso general Anko Hallo, los guerreros chankas llegaron a la actual ciudad amazónica de Lamas donde, mezclándose con diversos grupos nativos, dieron origen al presente pueblo kichwa². Según algunos, la ascendencia andina de los nativos de Lamas puede explicar por qué

\footnotetext{
J. S., entrevista: Tarapoto, 7 de abril 2018.

Estos grupos nativos también se conocen como «quechuas-lamistas», ya que la mayoría de ellos vive en el barrio Wayku, ubicado en la ciudad de Lamas. En la literatura analizada también está presente el nombre «llacuash» (Scazzocchio, 1979); sin embargo, este término ha caído en desuso en gran parte de la región, aunque en el área de Sisa parece existir todavía (Cachique Amasifuén, 2007). El antropólogo Luís Calderón Pacheco se refiere a esta población definiéndola «kechwa»o «kichua» (Calderón Pacheco, 2003).
} 
este pueblo, que vive en una región amazónica, habla una variante del idioma quechua, un idioma principalmente difundido en los Andes $^{3}$.

Durante años, esta reconstrucción histórica ha sido cuestionada por varios antropólogos, médicos y lingüistas (Wiess, 1949; Scazzocchio, 1979; Figueróa, 1904; Doerty 2007; Calderón Pacheco, 2003), quienes están convencidos de que los actuales kichwa son, en realidad, descendientes de una serie de poblaciones amazónicas obligadas (por misioneros jesuitas y franciscanos) a vivir juntas en las llamadas «reducciones de indios» ${ }^{4}$, donde se vieron forzadas a aprender el quechua como lengua franca.

Ante la discrepancia entre una narración producida por una importante tradición oral y datos de origen histórico y cultural, los estudios genéticos intervinieron en el debate tratando de poner fin a la discusión. Mediante el análisis del ADN uniparental ${ }^{5}$ de los nativos de San Martín, y a través de su comparación con algunas muestras recolectadas en el departamento de Huancavelica y otras obtenidas de los pueblos originarios amazónicos vecinos ${ }^{6}$, los científicos pudieron demostrar que el mito del origen chanka no tiene ningún fundamento biológico ${ }^{7}$. Con este

3 Esta variante, que se remonta a la rama IIb del quechua, no solo se habla en el departamento de San Martín: el kichwa canelo, en Ecuador, se expresa con el mismo idioma, el inga (en Colombia) pertenece a la misma familia y, finalmente, en la región de Loreto hay algunos grupos indígenas que lo utilizan (Doerty, 2007, p. 10).

4 Las reducciones de indios, o misiones, eran órganos administrativos a través del cuales se intentaba controlar, con fines de evangelización, diferentes pueblos indígenas reunidos en un solo territorio. En la ciudad amazónica de Lamas, la misión fue cerrada en 1635.

5 Cuando los genetistas de poblaciones intentan individualizar las etapas de formación de las agrupaciones humanas actuales, se refieren a los llamados «perfiles genéticos uniparentales», es decir, al patrimonio genético heredado de solo uno de los padres. Esta expresión se refiere al estudio de algunas regiones específicas del ADN mitocondrial (ADNmt) y del ADN del cromosoma Y. El ADN biparental (transmitido por ambos padres) no es completamente heredado por los hijos, ya que sufre un proceso de mezcla e intercambio en las células destinadas a reproducción. Por el contrario, el ADN uniparental se transmite de forma integral, de generación en generación. Esto hace que el ADNmt y el cromosoma Y sean candidatos ideales para el análisis y estudio de la historia biológica de las poblaciones contemporáneas. Las únicas variaciones sufridas por estas porciones de $\mathrm{ADN}$ son las debidas a las mutaciones aleatorias que se acumulan secuencialmente durante y después del proceso de dispersión humana en las distintas áreas geográficas (Santachiara-Benerecetti, 2001, p. 57).

6 Entre ellos, los awajunes, los kukamas, los jívaros, y los kichwas del Ecuador (Sandoval et al., 2016, pp. 92-93).

7 Las investigaciones, por un lado, identificaron una similitud entre la herencia genética kichwa y la de algunos grupos indígenas amazónicos. Por otro lado, descartaron una estrecha correlación entre los haplogrupos kichwa y los de aquellos que, en los Andes, se autoidentifican hoy en día como descendientes de los chankas (Sandoval et al., 2016). 
artículo me propongo identificar algunas de las consecuencias sociales y políticas de este singular encuentro entre los genetistas y la población nativa kichwa.

Son muchos los etnógrafos que, en los últimos años, se han dedicado a la observación de las derivaciones sociopolíticas de los resultados producidos por la biología molecular. La antropología médica, por ejemplo, se ha centrado en los mecanismos de producción de biosocialidades (Rabinow, 1996) y ha revelado cómo algunos datos de origen genético puedan forjar agrupaciones humanas que se autoidentifiquen como cerradas por fronteras biológicas. Al mismo tiempo, la antropología del parentesco ha analizado las poderosas implicaciones que las nuevas tecnologías reproductivas pueden tener sobre la percepción social de los lazos familiares. Finalmente, varios antropólogos culturales y sociales han centrado su atención en las políticas de la identidad, nacidas en contextos indígenas o locales, tras la difusión de los resultados producidos por la paleoantropología y la genética de poblaciones (Kent y Santos, 2012; Kent, 2013; Trupiano, 2013; Tamarkin, 2014; Solinas, 2015).

Aunque se hayan dedicado a diferentes aspectos de las relaciones entre genetistas y agrupaciones humanas, todas estas investigaciones etnográficas parten de una premisa fundamental: la de considerar el ADN como un objeto etnográfico cualquiera y analizarlo exactamente como se haría con una práctica social, una representación colectiva o un conocimiento tradicional. Por esa razón, los estudios aquí citados no se centran mucho en el producto científico en sí (es decir en el mismo resultado de los análisis biomoleculares), sino más bien en la forma como este producto es manejado, en un plano simbólico, por las poblaciones locales (Simpson, 2000, p. 3). De hecho, como demuestran diferentes autores, el ácido desoxirribonucleico, lejos ser un objeto neutral, puede contribuir a plasmar - o simplemente dirigir - las elecciones políticas de algunos actores sociales. En el caso de los kichwa de San Martín, por ejemplo, las investigaciones biomoleculares han sido recientemente empleadas como una importante herramienta estratégica, útil para ayudar a los nativos con sus reivindicaciones territoriales.

En este artículo propongo pasar por tres etapas diferentes. En primer lugar, deseo mostrar la centralidad del cuento genético-ancestral dentro del panorama político actual de la región San Martín. En las siguientes páginas mostraré cómo, mediante la participación en talleres ofrecidos por ONG y agencias locales o extranjeras, los líderes nativos tienden a adquirir el discurso biológico. Esto les sirve para contrarrestar la historia de su origen chanka y demostrar, de una vez por todas, que los kichwa no son migrantes $y$, por lo tanto, tienen derecho a utilizar sus propios «territorios ancestrales» ubicados en la selva de San Martín. 
En un segundo momento intentaré resaltar que la relación entre los conceptos de «ascendencia», «indígenismo» y «territorio» no traduce una forma propiamente nativa (o amazónica) de ver el mundo. Por el contrario, esa es adquirida estratégicamente por los líderes locales, gracias al trabajo de algunos mediadores culturales ( $\mathrm{ONG}$, abogados y profesores bilingües). Estos últimos, al implementar un proceso de vernacularización (Marry, 2006) del lenguaje jurídico y científico, favorecen una conexión entre los nativos kichwa y una «red indígena transnacional» (Niezen, 2003, p. 2), que les permite acceder a circuitos supranacionales capaces de vincular a los estados y a las regiones a reconocer sus derechos específicos (Sapignoli, 2018).

En la última porción de este ensayo intentaré, finalmente, mostrar cómo una parte de la población indígena kichwa no parece adquirir acríticamente este discurso político-estratégico (basado en la retórica de la primacía temporal) y siga considerando sus propias reivindicaciones territoriales a través de una concepción «relacional» del medio ambiente (Ingold, 2000). Así, a pesar de haber asimilado el cuento genético-ancestral, muchos nativos de San Martín lo van remodelando a la luz de una concepción más amazónica del territorio. Este último, lejos de ser considerado una herencia transmitida de una generación a otra, es percibido como una compleja red de relaciones (presentes y activas) entre los individuos vivos, los antepasados y las plantas medicinales.

Este caso etnográfico pone de relieve un gran malentendido sobre los conceptos de «ascendencia»y «territorio», cuyo significado, en el ámbito indígena, supera los límites impuestos por la jurisdicción nacional y la terminología legal. De hecho, es en la presencia constante de la intencionalidad de los antepasados donde se puede identificar el real significado del vínculo ancestral entre los indígenas kichwas y su territorio.

\section{EL DESCUBRIMIENTO DE LOS ORÍGENES Y LA DEFENSA DEL «TERRITORIO ANCESTRAL»}

Ya, terminemos rápido esta reunión, porque quiero escuchar lo que piensan los científicos: quiero conocer mis orígenes. ¡Quiero saber en qué sentido soy indígena!'.

Unas semanas después de mi llegada a la región de San Martín, una organización sin fines de lucro de la ciudad de Tarapoto me invitó a participar a una asamblea

8 G. S., reunión de CODEPISAM: barrio Wayku de Lamas, 20 de marzo de 2018. 
nativa9. El 20 de marzo de 2018, a las nueve de la mañana, los miembros de la federación indígena CODEPISAM ${ }^{10}$ se reunieron en el barrio Wayku de la cuidad de Lamas ${ }^{11}$, en la sede de FEPIKRESAM ${ }^{12}$. A partir de este encuentro, el presidente de dicha organización quiso difundir los resultados de las investigaciones biomoleculares mencionadas en el párrafo precedente (Sandoval et al., 2016; Barbieri et al., 2017). De esta manera esperaba que los líderes de las federaciones nativas tomaran conciencia del discurso científico que refuta la existencia de un vínculo biológico entre los kichwa de San Martín y los actuales habitantes de Huancavelica, que se autoidentifican como descendientes de los guerreros chankas y pokras.

Unos meses más tarde, algunos miembros de la Cooperación Alemana GIZ ${ }^{13}$ propusieron una serie de seminarios de capacitación, dedicados a estos temas, y reunieron a los líderes indígenas del distrito de Chazuta ${ }^{14}$, del barrio Wayku y de la provincia de El Dorado ${ }^{15}$. El objetivo de dichos eventos se configuraba, según las perspectivas de GIZ, en la recuperación de una supuesta identidad indígenoamazónica, a través de la difusión de los estudios realizados por historiadores, lingüistas y antropólogos. Para este propósito, los proponentes de los seminarios decidieron concentrarse en difundir «una historia indígena descolonizada» ${ }^{16}$, en recordar el pasado traumático de los kichwas y en señalar cómo el barrio Wayku de Lamas se formó a partir de la reducción de indios establecida en 1630 por los jesuitas ${ }^{17}$. Durante estos encuentros (titulados, de manera evocadora, «¿De dónde venimos?») se presentaron también, de forma simplificada, las investigaciones realizadas por los genetistas peruanos y extranjeros:

\footnotetext{
Esta organización colabora los kichwas de Lamas desde hace años.

Coordinadora de Desarrollo y Defensa de los Pueblos Indígenas de la Región San Martín.

El barrio nativo Wayku, de la ciudad amazónica de Lamas, reúne a la mayoría de la población nativa actual.

12 Federación de Pueblos Indígenas Kichwas de la Región San Martín.

13 Deutsche Gesellschaft für Internationale Zusammenarbeit.

14 Chazuta es uno de los distritos en que se divide la región San Martín. Su capital, la ciudad de Chazuta, se encuentra a $41 \mathrm{~km}$ de la ciudad de Tarapoto, a orillas del río Huallaga.

15 La provincia de El Dorado pertenece a la región San Martín y su capital es la ciudad de San José de Sisa, ubicada a $54 \mathrm{~km}$ de la ciudad de Tarapoto.

16 Esta expresión es utilizada, hoy en día, tanto por algunos líderes nativos como por miembros de las asociaciones y las ONG que trabajan en el territorio.

17 En particular, los organizadores enfatizaron la importancia de reconocer la antigua presencia de diferentes grupos nativos en todo el territorio de San Martín y, consecuentemente, de recordar a los actores sociales involucrados su derivación amazónica.
} 
El patrimonio genético de los kichwas se parece al patrimonio de los awajunes, cocamas y jivaros y el origen de este pueblo es probablemente amazónico. El patrimonio genético andino, al contrario, es muy diferente [...] así que se puede confirmar que entre los kichwa de Lamas no hay antepasados chankas. Esto es, por lo menos, lo que hoy en día se cree. Hay que seguir estudiando, pero según la ciencia actual, ustedes no descienden de los chankas. No hay afinidad ${ }^{18}$.

Parece natural, en este punto de la discusión, preguntarse por qué tanto entusiasmo ante una investigación que, de hecho, se limitó a certificar (bajo un punto de vista biológico) lo que ya habían postulado lingüistas, arqueólogos y etnógrafos $^{19}$. Los mediadores culturales (ONG, antropólogos, funcionarios, abogados y profesores bilingües) que trabajan con el pueblo kichwa, están acostumbrados a dialogar con organismos regionales, estatales e internacionales: conocen, por tanto, el peso político que tienen los discursos que se centran en cuestiones «étnicas» o «indígenas». En ese tipo de panorama, los modelos de biosocialidad (Rabinow, 1996) que la genómica parece poner a disposición se transmutan en conceptos «no solamente buenos para pensar [sino también, en herramientas buenas] para actuar» (Palmié, 2007, p. 210). La nueva narración de los orígenes (propuesta por los genetistas) es captada, por esa razón, como una importante oportunidad para impulsar algunas estrategias de autoetnización que, durante los últimos años, se están promocionando entre los nativos kichwa:

Quisimos, con la organización, hacer un esfuerzo para que la gente empiece a recuperar su memoria ancestral. Y se empiece a comprender que no es que viene de otro lado: que esa tierra es suya. Porque, de otra manera, se empieza a pensar que «venimos del sur y que somos migrantes, como calquiera»: por eso ahora hay una crisis. Al contrario, ellos son indígenas. Y estudios que expliquen lo que dicen los genetistas pueden ayudar en las cuestiones políticas ${ }^{20}$.

Para comprender el significado de estas palabras, parece importante proponer el análisis de un enfrentamiento territorial que está involucrando, hoy en día, a la población indígena aquí analizada. El que se va a describir no es el único conflicto que la población kichwa de San Martín está afrontando; sin embargo, la discusión de este caso específico puede proporcionar un ejemplo etnográfico útil: analizada críticamente, esta disputa permite reflexionar sobre el papel de las investigaciones genéticas dentro de las arenas políticas.

\footnotetext{
18 Funcionario de GIZ: taller «¿De dónde venimos?», 7 julio 2018.

19 Véanse las consideraciones reportadas en el párrafo anterior.

20 D.V., entrevista: Tarapoto, 16 de marzo 2018.
} 
Desde el año 2017, los nativos kichwa de diferentes comunidades están viviendo un conflicto territorial debido al establecimiento, en la región San Martín, del Área de Conservación Regional de la Cordillera Escalera (ACR-CE). Este Parque Natural Protegido cubre actualmente una superficie de 149870 hectáreas y fue instituido el 25 de diciembre del año $2005^{21}$, con el objetivo de preservar y «proteger los recursos naturales y la diversidad biológica de los frágiles ecosistemas que se encuentran en la Cordillera Escalera» (SERNANP, 2013, p. 35) ${ }^{22}$. Tras su nacimiento, algunas agrupaciones kichwas se sintieron despojadas de sus tierras, utilizadas tradicionalmente para realizar algunas de las principales actividades de subsistencia (la caza, por ejemplo, la cría de pequeños animales, el policultivo u, ocasionalmente, la pesca).

Una de las comunidades más afectadas por la presencia de dicha área de conservación regional es, sin duda, la de Nuevo Lamas de Shapaja, cuyos habitantes denuncian haber obtenido del gobierno regional de San Martín ${ }^{23}$ título de propiedad sobre un territorio fragmentado y considerablemente insuficiente. En el año 2016, en efecto, la Dirección Regional de Agricultura de GORESAM otorgó a la comunidad nativa de Nuevo Lamas título de propiedad sobre poco más de 31 hectáreas $^{24}$, que corresponden al 1,95\% del suelo tradicionalmente utilizado por la población nativa. Las restantes 1620 hectáreas de tierra (la mayoría de las cuales se superponen al Área de Conservación Regional de la Cordillera Escalera) fueron entregadas a los habitantes de Nuevo Lamas de Shapaja con un simple contrato de cesión de uso forestal lo cual, lamentablemente, desfavorece el pleno desarrollo del modus vivendi de dicha Comunidad Nativa ${ }^{25}$.

Por esta razón, en el mes de agosto del año 2017, Nuevo Lamas de Shapaja y el Consejo Étnico de los Pueblos Kichwa de la Amazonía (CEPKA) presentaron una acción de amparo ante el Primer Juzgado especializado en lo Civil, de la Corte Superior de San Martín. A través de esta demanda, CEPKA y la comunidad

21 Decreto Supremo 045-2005-AG 2005.

22 El proceso para la creación de la ACR-CE se remonta al año 1992 cuando, después de haber reconocido la Cerro Escalera como zona de alto potencial ecológico, se creó el Bosque de Protección Regional Cordillera Escalera (BPR-CE), que entonces cubría solo 190 hectáreas. La Cordillera Escalera es una cadena montañosa, ubicada al norte del departamento de San Martín, que divide las dos regiones amazónicas peruanas: Selva Alta y Selva Baja.

23 GORESAM.

24 En concreto 31,3048 hectáreas.

25 Este contrato tiene graves limitaciones que impiden muchas de las actividades tradicionales relacionadas con el bosque de San Martín. 
kichwa del distrito de Shapaja solicitaron al GORESAM ${ }^{26}$ el reconocimiento inmediato del título de propiedad sobre todo el territorio ancestral de Nuevo Lamas, incluidas las tierras otorgadas a la comunidad con simple contrato de cesión de uso forestal. Al mismo tiempo, acusaron al Ministerio de Agricultura de no haber dictado criterios nacionales unívocos para la concesión de los títulos de propiedad a las Comunidades Nativas y Campesinas, permitiendo que cada Gobierno Regionál definiera estos parámetros de forma independiente ${ }^{27}$. Finalmente, al gobierno regional, a las autoridades de la Cordillera Escalera y al Ministerio de Ambiente, CEPKA y Nuevo Lamas atribuyeron la responsabilidad de no haber garantizado el derecho de consulta previa antes la creación del Área de Conservación Regional.

Todo esto representó (según CEPKA y la comunidad interesada) una clara violación de algunos derechos constitucionales del pueblo kichwa; entre ellos, el derecho a la identidad y a la integridad (social, cultural y física), el derecho a la propiedad sobre un territorio ancestral y el derecho a la determinación de su propio modelo de desarrollo. El 15 de agosto de 2018, la Corte Superior de Justicia de San Martín declaró infundada esta demanda de amparo.

En medio de este conflicto, durante el año 2017, GORESAM promovió una campana mediática bastante violenta dirigida a presentar a los pueblos nativos como una amenaza para el medio ambiente, protegido por el ACR-CE ${ }^{28}$. En algunos casos, la propaganda describía a las autoridades indígenas como títeres de las compañías petroleras ${ }^{29}$. Varios actores involucrados en el conflicto, además,

Más precisamente, lo solicitaron a la Dirección Regional de Agricultura.

En el caso de Nuevo Lamas de Shapaja, esto llevó precisamente a la celebración de contratos desventajosos de cesión de uso forestal de las tierras.

El 30 de marzo de 2018 FECONAU (Federacíon de Comunidades Nativas del Ucayali y Afluentes) y CEPKA presentaron ante el Comité para la Eliminación de la Discriminación Racial de las Naciones Unidas (CERD) lo que se define como shadow report. Se trata de un informe alternativo sobre la situación de los grupos nativos frente al Estado peruano. En este documento destaca la incapacidad del gobierno estatal para responder las recomendaciones anteriores del CERD, con un enfoque específico en las regiones de Ucayali y San Martín. Dentro de este documento, los firmantes denuncian (entre otras cuestiones) el daño sufrido por el pueblo nativo kichwa, debido a dicha campaña discriminatoria. Las informaciones aquí reportadas provienen tanto de las entrevistas realizadas en el campo como del análisis del shadow report de 2018. El documento se puede consultar al enlace siguiente: http://www.forestpeoples.org/ sites/default/files/documents/CERD_Peru_ShadowReport_95_29thMarch2018_Eng1_1.pdf. Según los detractores, el conflicto territorial y el lento proceso de titulación habrían generado un vacío institucional: esto habría transformado las tierras de la Cordillera Escalera en ambientes extremadamente vulnerables, a merced de las actividades extractivas. De esta forma, GORESAM difundió la opinión, compartida por varios actores sociales mestizos, según la 
comenzaron a cuestionar la legitimidad de las peticiones territoriales del grupo kichwa, haciendo implícita o explícita referencia al presunto origen andino de la población nativa ${ }^{30}$. A pesar de que en el estudio justificatorio para el establecimiento del ACR-CE se citen ambas versiones de la historia del origen kichwa, la narrativa en torno a la leyenda de la migración andina se convirtió, para algunos, en un elemento útil para desacreditar el derecho al reconocimiento territorial de los nativos ${ }^{31}$. Incluso, en las redes sociales, ciertos exponentes del Frente para la Defensa de la Cordillera Escalera empezaron a utilizar el argumento de la ascendencia chanka de los kichwas, para representarlos como «enemigos del pueblo de San Martín y de la Cordillera Escalera que tienen la costumbre, típica de la sierra, de cortar árboles» ${ }^{32}$.

Los ejemplos aquí citados destacan hasta qué punto el discurso sobre los supuestos «orígenes étnicos» puede volverse central en las arenas políticas. Ante una narración - propuesta por ciertos exponentes del gobierno regional, que ven en la presunta identidad diferencial andina una razón suficiente para contraponerse a los reclamos territoriales kichwa-, algunos líderes indígenas se sienten, hoy en día, autorizados a utilizar el mismo discurso político-ancestral para reclamar su derecho a ser escuchados. Como ha sido evidenciado por diferentes antropólogos contemporáneos, en efecto, las investigaciones de biología molecular (reinterpretadas por un público no experto) parecen ser capaces de decir algo significativo sobre el presente y el futuro de las poblaciones involucradas (y, por lo tanto, también sobre sus opciones políticas), en virtud de la reconfiguración de su pasado compartido (Kent, 2013; Trupiano, 2013; Tamarkin, 2014). Refutar el mito de los orígenes chanka utilizando una nueva narrativa científica permite a la minoría discriminada asumir conscientemente su propia identidad diferencial como objeto de reivindicación política, comunicando públicamente un mensaje en el que se reivindica la la «legitimidad indígena» y la «irregularidad del Estado» (Mouriès, 2014) o, en este caso, del gobierno regional:

Mucha gente, desde GORESAM, dice que somos de los chankas. Pero si ves la cosa desde el punto de vista de los genetistas, eso te hace teorizar y te hace ver que no somos migrantes, tampoco. Que los nuestros son... son territorios

cual los pueblos indígenas solían contribuir (directamente o indirectamente) a la explotación de los recursos ambientales.

30 M.B., entrevista: Lamas, 8 de mayo de 2018.

31 «El gobierno regional nos dice "ustedes no pueden pedir nada en la Cordillera Escalera, porque vinieron migrando a estas zonas" (S.C., entrevista: Lamas, 10 de abril de 2018).

32 FECONAU y CEPKA, 2018, p. 18. 
ancestrales, ¿no? Que los abuelos y los tatarabuelos ya han estado aqui viviendo, hace muchos siglos [...]. El hecho que queremos territorio no es de ahora. Lo que el Estado pretende es desconocer esta posición de los kichwas. Por eso dicen: "Ustedes son recientes. No viven aqui desde antes». Esto, al contrario, ya confirma que sí: estamos aquí desde muchos años ${ }^{33}$.

\section{ANCESTRALIDAD, INDIGENISMO Y TERRITORIO}

La cuestión de la legitimidad de los reclamos kichwa (basada en una supuesta ancestralidad genéticamente certificada) o, por el contrario, la negación de cualquier derecho sobre las tierras pertenecientes a la ACR-CE (por causa del origen andino tradicionalmente atribuido a los nativos de San Martín), plantea una serie de preguntas sobre las relaciones entretenidas entre los conceptos de «indigenismo», «ascendencia» $\mathrm{y}$ «territorio». En las palabras citadas, pronunciadas por un líder nativo que apoyó a los genetistas con la recolección de sangre y saliva, aparece una idea que conecta a todos estos términos y que, por lo tanto, merece la pena ser analizada. Se trata del concepto de «autoctonía». Este último se configura como la creencia según la cual las agrupaciones humanas derivan su derecho a vivir en un determinado ambiente en cuanto «siempre han estado ahí», y sus antepasados, que habitaban esos lugares antes que ellos, fueron quienes entregaron en sus manos el territorio que, legítimamente, reclaman ${ }^{34}$.

Esta idea, así como la referencia a una supuesta «autenticidad indígena», a una «cultura tradicional» o a un «idioma originario», es cada vez más presente en el contexto amazónico aquí observado. Es frecuente, por ejemplo, escuchar a profesores bilingües promover la recuperación de una lengua «ancestral» kichwa, o a autoridades locales apoyar encuentros entre los llamados «abuelos» nativos, con la finalidad de valorar sus «conocimientos y su cultura tradicional» $»^{35}$. Esto parece sugerir que tales elementos traducen una modalidad propiamente nativa de autopercepción y de representación del mundo. Sin embargo, la noción de «autoctonía» ha entrado recientemente a formar parte del horizonte político kichwa. Asimismo, la identificación indígena de los actores locales representa una novedad relativa: hasta la década de 1990, diferentes comunidades de San Martín

\footnotetext{
33 F. C., entrevista: Lamas, 14 de mayo 2018.

34 En virtud de esta convicción, los pueblos «indígenas» u «originarios» son presentados frecuentemente como los «únicos hijos verdaderos de una cierta tierra [ocupada]» (Bettini, 2011, p. 43).

35 Promovidos frecuentemente por ONG locales y extranjeras u organizaciones sin fines de lucro.
} 
renunciaron a numerosas ventajas políticas y territoriales para no ser catalogadas oficialmente, por el Estado peruano, como «pueblos indígenas» ${ }^{36}$. Siguiendo las reflexiones aquí reportadas, queda claro que todas estas narraciones, en la selva alta peruana, se configuren como el resultado de una adquisición estratégica de discursos para la defensa de los derechos humanos, nacidos en el escenario internacional y difundidos, posteriormente, en el contexto político local ${ }^{37}$.

Analizando algunas de las investigaciones propuestas por las Naciones Unidas, es posible, por ejemplo, identificar una primera referencia a la íntima relación entretejida entre los conceptos de «indigenismo», «territorio» $\mathrm{y}$ «ancestralidad». $\mathrm{Al}$ respecto, parece sumamente interesante observar un estudio elaborado por el ecuatoriano José Martínez Cobo, que propone una definición inicial y operativa de «pueblos indígenas $»^{38}$. Leyéndolo atentamente, es posible observar cómo el idioma hablado, la cultura tradicional y la ascendencia compartida se consideran factores determinantes para la individuación de un grupo nativo. Además, en lo que concierne a los antepasados, Martínez Cobo plantea en este documento, por primera vez, la centralidad del dato biológico, relacionado con la idea de una «ocupación primordial» de las tierras ${ }^{39}$.

36 Actualmente, las comunidades indígenas de San Martín (kichwa, shawi y awajun) reconocidas oficialmente por el Estado peruano son 106. De ellas, 74 pertenecen al grupo lingüístico kichwa. Sin embargo, a partir de 1997, solo quince de ellas fueron tituladas: catorce comunidades afiliadas a la federación FEPIKRESAM fueron tituladas al final de la década de 1990 y Nuevo Lamas de Shapaja (comunidad perteneciente a la federación CEPKA) obtuvo el título solo en 2016. La razón por la cual solo el 19\% de las agrupaciones kichwa tiene título oficial se puede encontrar también en la gran desconfianza que mostraron los habitantes de estos territorios. Muchas agrupaciones kichwa, al principio de la década de 1990, optaron por su propio reconocimiento como «centros poblados» y no como "Comunidades Nativas". Un Centro Poblado (también conocido como Caserío) representa, a diferencia de una Comunidad Nativa, un lugar del territorio nacional, rural o urbano, cuyos habitantes están vinculados simplemente por intereses comunes. Esto originó que los nativos de San Martín no fueran identificados directamente como agrupaciones indígenas o «tribales», como se afirma en la Ley 22175 .

37 Principalmente por los mencionados mediadores culturales, peruanos o extranjeros.

38 En el año 1970, la Sub-Commission on Prevention of Discrimination and Protection of Minorities, de las Naciones Unidas, le encargó la elaboración de un informe para identificar medidas nacionales e internacionales que permitieran la eliminación de la discriminación sufrida por diferentes poblaciones nativas en el mundo. El documento, presentado entre 1981 y 1983 , aborda una amplia gama de cuestiones, incluida una primera definición de «pueblo indígena». «El elemento biológico, o el hecho de descender de miembros de la población nativa de un país, es siempre presente cuando personas o grupos se describen como "indígenas", "autóctonos", “aborígenes" o “indios”» (Martínez Cobo, 1982, p. 15). 
A pesar de que los análisis de este autor no pueden aplicarse a todos los contextos nativos y de que a menudo hayan sido cuestionados por los pueblos indígenas o por los organismos estatales ${ }^{40}$, el peso político e ideológico de sus reflexiones es indudable, en particular en lo que concierne a la identificación de criterios unívocos y compartidos para la individuación de una «subclase internacional [...] de los pueblos indígenas» (Niezen, 2003, p. 11). Se considere, a modo de ejemplo, el Convenio 169 de la International Labour Organization, adoptada por las Naciones Unidas en 1989 y ratificada en el Perú en 1993. En este tratado se atribuye a todas las agrupaciones indígenas un cierto valor diferencial, fácilmente identificable en los elementos mencionados por Martínez Cobo en su informe ${ }^{41}$.

De acuerdo con lo que se acaba de decir, parece útil analizar el movimiento nativo, entendido como un «nuevo fenómeno global» (Niezen, 2003, pp. 1-28). En las batallas territoriales llevadas a cabo por los pueblos amazónicos y andinos, no es raro hoy en día observar líderes locales hacer uso de un discurso políticoindígena que no indique simplemente la pertenencia a un grupo étnico-local ${ }^{42}$. Esto queda demostrado en las muchas referencias a la Declaración de las Naciones Unidas sobre los Pueblos Originarios, al mismo Convenio 169 o a la Ley del Derecho a la Consulta Previa. Aunque, a menudo, los líderes indígenas reconozcan la importancia de encontrar su camino específico ${ }^{43}$, no se puede negar que muchas de sus reivindicaciones se refieren a una «subjetividad indígena general» (Mouriès, 2014, p. 22). Esta última concibe la «identidad ancestral» como un concepto ambivalente, cuyo significado puede mutar según el punto de vista adoptado.

Desde una perspectiva interna, la ascendencia sigue representando el conjunto histórico de los antepasados (con o sin nombre) de un grupo humano particular, que funcionan como verdaderos «puentes» capaces de mantener la cohesión de comunidades enteras (Zerubavel, 2004). Por otro lado, como señalan varios antropólogos contemporáneos (Niezen, 2003; Surrallés, 2009; Sapignoli, 2018), recurrir a una idea genérica de «ascendencia» (no importa que sea amazónica, andina o africana) hace que los actores sociales involucrados se sientan parte de

40 La definición de pueblo indígena «no encaja bien, por ejemplo, en aquellas áreas del sudeste asiático en las que se han registrado desplazamientos y movimientos de personas a través de las fronteras nacionales» (Niezen, 2003, p. 20) y ha sido cuestionado por aquellos estados, como India, que no aceptan la autodefinición de los indígenas.

41 Vease el artículo 1 del Convenio 169.

42 Como se puede observar en diversos estudios dedicados a los procesos de autoetnización de las poblaciones nativas (Espinosa, 2009; Zerga, 2010; Romio, 2010; Kent, 2013).

43 Como señalan las numerosas alusiones a la recuperación del idioma tradicional o a la historia local. 
una comunidad «glocal» (Favre, 2005). Contra «la gris uniformidad impuesta por los estados nacionales» (Niezen, 2003, p. 2), el indigenismo se presenta, entonces, como una categoría analítica transnacional, capaz de revelar algo significativo sobre las identidades locales.

Según el antropólogo Adam Kuper, es precisamente a partir de este particular posicionamiento del movimiento indígena (en constante tensión entre la dimensión local y global) que puede desarrollarse el mayor peligro de esencialización identitaria. Los mediadores culturales portavoces de los derechos nativos - afirma el etnógrafo - siguen luchando por «el reconocimiento de formas alternativas de entender el mundo, pero irónicamente lo hacen utilizando el idioma [típico] de la cultura occidental» (Kuper, 2003, p. 395). Se consideren los citados datos genéticos que, en los talleres ofrecidos a los dirigentes nativos, se convierten en una herramienta estratégica para individuar pistas sobre la legitimidad de los reclamos territoriales. Pistas escondidas dentro del texto nucleótidico ${ }^{44}$. En este contexto, la noción misma de «ancestralidad» corre el riesgo de convertirse en una manera de promover la vieja concepción de pertenencia territorial, entendida cómo blood and soil (Kuper, 2003, p. 395), «sangre y tierra».

Ante estas reflexiones, parece oportuno precisar lo siguiente. El autor está consciente de que los mediadores culturales y las federaciones indígenas están utilizando hoy este tipo de lenguaje esencialista y ancestral con el fin de abrirse un camino jurídico en el derecho nacional existente. El análisis crítico que se presenta en estas páginas no puede, por tanto, prescindir de una representación realista del escenario estratégico interactivo y debe tomar en cuenta a los destinatarios efectivos de la comunicación política. De hecho, es poco creíble pensar que los mediadores culturales, que trabajan en estrecho contacto con los pueblos indígenas, no sean conscientes de las grandes limitaciones y aporías que caracterizan las estrategias políticas basadas en los conceptos de «autoctonía» y de «territorio ancestral». Sin embargo, el uso de estas estrategias permite, realísticamente, mantener un diálogo con las autoridades regionales y estatales sobre cuestiones relacionadas con el acceso a los recursos.

A través del examen de este contexto etnográfico, por tanto, no se pretende argumentar que el uso político de los estudios biomoleculares sea la consecuencia de una representación ingenua del mundo y del territorio operada tanto por los líderes nativos como por las ONG (nacionales e internacionales). Por el contrario,

44 Los nucleótidos son los «constituyentes elementales» (Cavalli-Sforza, 1996, p. 313) del ADN, presentes en cuatro variedades: adenina, citosina, timina, guanina (ACTG). 
estos últimos, insistiendo precisamente en el concepto de «primacía temporal», llevan a cabo una hábil operación política al revertir (y reutilizar como arma estratégica) una idea prestablecida por el derecho imperante en los estados nacionales. Más bien, lo que aquí se intenta argumentar es que dicha narrativa política no representa el único (y el más adecuado) horizonte de pensabilidad dentro del cual inscribir las investigaciones biomoleculares y los discursos ancestrales.

Por esa razón, el objetivo propuesto en el siguiente párrafo es identificar (a través de un caso etnográfico específico) algunas de las posibles articulaciones locales de las representaciones indígenas-ancestrales y observar la reelaboración nativa del discurso genético. Se considera necesario presentar una forma propiamente indígena de percibir y proponer este tipo de narración. Hoy, varias agrupaciones amazónicas son describidas a través de la retórica de la aculturación, retórica incorporada frecuentemente también por las mismas poblaciones nativas. Según este paradigma, el contacto con el occidente habría generado una cierta actitud pasiva que llevaría a los indígenas a incorporar en sus propias narrativas tradicionales, todo tipo de elementos proveniente de contextos ajenos. Esto, obviamente, se aplicaría también al uso (por los líderes nativos) de discursos políticos nacidos en el ámbito internacional o a la aceptación acrítica de las investigaciones biomoleculares. Esta pasividad, desmentida por varios autores contemporáneos (Gow, 1991; Belaunde, 2008; Chaumeil, 2010), tampoco encuentra espacio en las reflexiones aquí presentadas. De hecho, la población kichwa, lejos de importar acríticamente este discurso político-biológico, muestra una gran creatividad cuando se trata de remodelar tales narrativas a la luz de una concepción local de las ideas de «ascendencia» $\mathrm{y}$ «territorio».

\section{PARA ENREDAR LOS ÁRBOLES GENEALÓGICOS ${ }^{45}$}

Durante mi trabajo de campo tuve la oportunidad de visitar diferentes Comunidades Nativas. La familia con la que viví, en el Wayku, posee algunas chakras cerca de Sisa y San Miguel del Río Mayo. Además, junto con amigos y conocidos, viajé bastante buscando otros llaktakun ${ }^{46}$ que me pudieran recibir. En el mes de mayo del año 2018, durante una de estas excursiones, conocí a una familia de

45 Deleuze y Guattari, 1988, p. 11.

46 Pueblos, comunidades. El sufijo - kuna, en kichwa, es un pluralizadór. 
curanderos que vive en una comunidad nativa cerca de la ciudad de Chazuta ${ }^{47}$. Me instalé en su habitación durante unas semanas y, posteriormente, decidí organizar mi investigación entre el Wayku y la pequeña comunidad.

La familia, desde hace algunas décadas, cuenta innumerables mitos de origen, con el objetivo de acreditar su pertenencia a una tradición chamánica ancestral. En estas páginas deseo recorrer una de estas leyendas: la que cuenta de un personaje mítico con poderes extraordinarios, al que todo el pueblo atribuye la fundación de la comunidad. Este cuento está claramente inspirado en la historia del origen andina de la población kichwa. Durante mi estadía tuve la oportunidad de escucharlo varias veces, antes y después de la divulgación (por los mediadores culturales) del trabajo de los genetistas.

Se dice que, tras la persecución inca, los antepasados de la familia de curanderos, junto a otros miembros de la población chanka, emprendieron una larga migración que, desde Huancavelica, los condujo a la ciudad de Chachapoyas y, posteriormente, a la selva alta. Según este mito, los antiguos viajeros lograron evitar la dominación del Tawantinsuyu en dos ocasiones: la primera tras la guerra chanka-inca del año 1438, y la segunda en el siglo XVI, cuando el Tawantinsuyu conquistó la fortificación de Kuelap, expulsando y dispersando la célebre civilización de los chachapoyas. Cuando llegaron en la actual ciudad de Tarapoto, los curanderos migrantes enfrentaron y derrotaron a las poblaciones autóctonas encontradas y, finalmente, pudieron establecerse, formando el mawka llakta («pueblo antiguo»). Sin embargo, la paz para ellos tardó en llegar: después de algunas décadas tuvieron que abandonar estos lugares, debido a la presencia de los colonizadores españoles.

Entonces mis padres y mis abuelos vinieron cerca de Chazuta, en busca de un lugar donde nadie les va a molestar, porque sabían que al mawka llakta, en cualquier momento, llegan los esclavizadores. Cuando mis ancestros llegaron acá, por esta parte de la quebrada, pues, es un lugar bien tranquilo: la selva, los animales, los peces en el río, decidieron quedarse para formar su chakra ${ }^{48}$.

Esta larga y tortuosa travesía solo pudo realizarse gracias al valiente guía de C.C., «un tío abuelo» ${ }^{49}$ con poderes sensacionales. Él tenía la capacidad de transfigurarse en varios animales depredadores para proteger a sus familiares y

47 En este ensayo prefiero no mencionar el nombre de la comunidad para no dañar la privacidad de mis informantes.

48 A.C., entrevista: Chazuta, 1 de junio 2018.

49 A.C., entrevista: Chazuta, 1 de junio 2018. 
proporcionarles comida. Una vez asentados en la pequeña comunidad cerca del río, con el paso de los años (y de los siglos), todos los miembros de la familia empezaron a envejecer y morir. Todos menos C.C., que solía transfigurarse en su animal favorito, el puma, para cazar. Con la llegada de la modernidad y de las armas de fuego, C.C. empezó a sentirse amenazado, porque sabía que algún cazador le habría disparado, un día u otro, encontrándolo en el bosque con la apariencia de un peligroso depredador. Así decidió transformarse, de una vez por todas, en un elemento del paisaje: «decidió que su alma y sus conocimientos los iba a poner en un árbol de lupuna, un árbol milenario que hoy está aquí en nuestra chakra $\rangle^{50}$. Hoy en día, los habitantes del llakta que descienden de C.C. suelen comunicarse con él, rindiendo homenaje a la centenaria lupuna y participando en ceremonias chamánicas a través de las cuales es posible ver a este mítico ancestro con la apariencia de un puma.

Regresando una segunda vez a la pequeña Comunidad Nativa, tuve la oportunidad de escuchar nuevamente esta historia de migración y fundación. En ese momento, GIZ y la organización sin fines de lucro de la ciudad de Tarapoto ya habían tenido la oportunidad de difundir los resultados de la investigación biomolecular, a través de reuniones, talleres y seminarios de formación. Para mi sorpresa, me di cuenta de que, a pesar de un rechazo inicial de la nueva narrativa históricobiológica, la «verdad» propuesta por los genetistas fue involucrada dentro del sistema mítico de la familia nativa. Las ramas ascendentes de su árbol genealógico se multiplicaron y la historia de la migración sufrió una especie de bifurcación, útil para incluir ambas las versiones del origen kichwa: la tradicional y la científica.

C.C., en esta nueva versión de la historia, en 1438, guió a sus familiares desde la selva ecuatoriana (exactamente cómo suponen los genetistas de las poblaciónes). Simultáneamente (y sin aparente contradicción), un nuevo personaje mítico, el Ayanku, los condujo desde el departamento de Apurímac hacia la selva de San Martín (de acuerdo con el cuento tradicional).

Acá hay muchas historias que parecen mitología, pero que son historias reales. Por ejemplo, la historia del puma. [...] Según nuestros abuelos, o sea... mi abuelo me contaba que su tatarabuelo le contaba, que había un personaje, un tío, que se llamaba C.C., que ha sido un superdotado que se transformaba en una pantera. Nosotros hemos migrado del Ecuador gracias a la habilidad de este personaje. [...] Y pasaban los años, y ese no se envejecía. La población

50 A.C., entrevista: Chazuta, 1 de junio 2018. A veces, hoy en día, sucede que los miembros de esta familia, especialmente durante las ceremonias chamánicas, vean a C.C. con la apariencia de gran puma. 
empezaba a crecer y se sintió amenazado [...] Entonces decidió convertirse en un árbol. C.C es la lupuna, y la lupuna es la pantera. Venimos del Ecuador, gracias a él, y venimos de los chankas. Pero en esta historia hay otro personaje, que llamamos el Ayanku y que probablemente no era descendiente de alguien de este mundo ${ }^{51}$.

El Ayanku fue, en su vida, un ser extremadamente solitario, y desapareció durante una noche tormentosa, dejando en su memoria una especie de piscina natural que la familia suele llamar el Ayanku uchku, el «agujero del Ayanku».

Esta historia nos obliga a reflexionar sobre una serie de cuestiones que intentaremos abordar brevemente en el transcurso de las siguientes páginas. La primera cuestión, la más macroscópica, se refiere a la posibilidad de manipular (sin ningún problema aparente) los árboles genealógicos. Esta puede remontarse a un rasgo interesante de la ascendencia indígena. Una característica que la distingue radicalmente del concepto de «ancestralidad», utilizado como herramienta estratégica en las arenas políticas (y conectado a las ideas de «herencia»y de «autoctonía»). Para investigar estas cuestiones nos podría ayudar el análisis del antropólogo Tim Ingold, quien en su obra The Perception of the Environment (Ingold, 2000) establece una primera distinción entre los que él define como «modelo genealógico» y «modelo relacional».

El primero, según la reconstrucción de Ingold, se configura como una forma típicamente occidental de percibir los lazos sociales y territoriales. Esta se caracteriza por una representación arbórea, capaz de captar e identificar gráficamente el concepto de «ascendencia» entendido como un elemento ahistórico y natural. Dentro de un modelo de este tipo, la identidad común, lejos de ser elegida por los actores sociales involucrados, se basa en la transmisión de «sustancias biogenéticas anteriores a la vida en el mundo» (Ingold, 2000, p. 133). Los ejemplos proporcionados en las páginas anteriores destacan el poder (político, simbólico y social) de este tipo de narrativas, en las que también la experiencia ancestral (representada por el idioma tradicional, los valores y la cultura inmaterial) se identifica como un elemento transmisible y heredable.

Por lo contrario, un «modelo relacional», con el rizoma en lugar del árbol, según el antropólogo inglés, puede describir con mayor precisión el sentido que los nativos tienen de sí mismos y de su lugar en el mundo. Esta imagen permite, a quien la utiliza, reflexionar «sobre las personas y las relaciones de una manera

51 A.C., entrevista: Chazuta, 17 de septiembre 2018. 
que se aleja de la linealidad estática y descontextualizada del modelo genealógico, concibiendo un mundo en [constante] movimiento» (Ingold, 2000, p. 140).

En lo que concierne el concepto de «ascendencia», es importante subrayar lo que sigue. La imagen del árbol se basa en la idea de que la existencia de cada individuo termine con su propia muerte y «colapse en un solo punto, que está conectado a otros puntos similares a través de linajes» (Ingold, 2000, p. 142). El rizoma, en cambio, permite describir las relaciones ancestrales en términos más complejos. Este tipo de representación no se configura como un movimiento de arriba hacia abajo, del pasado al futuro. Más bien, «las líneas de vida de diferentes seres se cruzan, se interpenetran, aparecen o desaparecen [...] en una profusión de conexiones transversales» (Ingold, 2000, p. 142). Dentro de una definición de historia familiar de este tipo, «antiarbórea» (Deleuze y Guattari, 1988, p. 21) y rizomática, no parece problemático que los seres humanos generen nuevos antepasados (como sucedió en el caso de la mítica figura de Ayanku) o que los progenitores míticos adquieran nuevos significados dentro de los relatos de sus descendientes (como ocurrió al «tío abuelo» C.C.).

Todo esto puede tener consecuencias directas también sobre las relaciones que los nativos entretejen con las llamadas «tierras ancestrales». En una concepción genealógica del territorio, el ambiente es considerado como un simple teatro, «una superficie que sirve de soporte a sus habitantes» (Ingold, 2000, p. 133). No se percibe como un espacio complejo de relación que sitúa al ser humano «en la historia, en el medio ambiente, en la economía y en la sociedad» (García Hierro y Surrallés, 2004, p. 12). Pensamos, por ejemplo, en la citada idea de «autoctonía» en nombre de la cual, a menudo, se invoca la recuperación de los llamados «recursos estratégicos»: el agua, los animales, las plantas y los paisajes, son considerados como simples legados materiales, transferidos a lo largo de una cadena genealógica. Por lo contrario, una representación rizomática de las relaciones humanas y familiares es capaz de ofrecer una percepción diferente del territorio. Ni el ambiente, ni los animales o las plantas que lo pueblan son considerados meros recursos, transmitidos de generación en generación.

Desde este punto de vista, puede ser útil recordar algunas teorías etnográficas recientes, que ven en la perspectiva ecológica un importante punto de apoyo para el análisis antropológico de algunos contextos indígenas (Viveiros de Castro, 1992; Fausto, 2002; Rival, 2004; Descola, 1992; 2005; Belaunde, 2008; AluliMeyer, 2014). En las últimas décadas, son muchos los etnógrafos que sienten la necesidad de analizar las instituciones políticas y familiares de los nativos, teniendo en cuenta que sus fronteras se extienden mucho más allá de los límites 
de la sociabilidad humana. Las investigaciones realizadas por Philippe Descola (1992), Eduardo Viveiros de Castro (1992) y por el ya mencionado Tim Ingold (2000) representan, desde este punto de vista, esfuerzos teóricos distintos, pero compatibles.

Por razones de espacio y de coherencia del texto, no es posible ofrecer aquí un examen completo de estas teorizaciones antropológicas. Sin embargo, es fundamental recordar que cada uno de estos autores ha sabido destacar cómo las agrupaciones de los Andes, de la cuenca amazónica, del bosque boreal y de las islas del Pacífico no adhieren al «dualismo estanco que, en nuestra cosmovisión, rige la distribución de los seres» (Descola 1997, p. 63). Más bien, comparten una peculiar concepción sistemática del ser y la biosfera, dentro de la cual los seres humanos, los animales, las plantas, los artefactos y algunos elementos del paisaje parecen constituir un único y vasto continuo relacional.

Como fue posible observar leyendo la historia de fundación de la pequeña Comunidad Nativa, la familia de curanderos kichwa no legitima su pertenencia al territorio a través de una retórica de la «autoctonía», entendida como «primacía temporal». Para ellos, no importa nada quién vino primero en la selva cerca de Chazuta: tanto la historia del origen ecuatoriano como la del origen andino admiten una migración e, incluso, certifican la antigua presencia de asentamientos humanos en los territorios conquistados. Lo que garantiza el «vínculo ancestral» entre el grupo kichwa y su territorio es la relación (presente y activa) que los individuos vivos entretejen con el medio ambiente y los seres no humanos que lo habitan.

Entre ellos también aparecen los ancestros, cuya existencia se actualiza, precisamente, a través del paisaje. Los hombres de la familia de curanderos a menudo afirman que pueden interactuar con C.C. y con los otros ancestros míticos ${ }^{52}$, pero lo hacen solo en lugares significativos. Por ejemplo, cerca del árbol de lupuna, del Ayanku uchku o dentro del tambo en el que los tatarabuelos solían ofrecer ceremonias a los visitantes.

Del mismo modo, son muchos los informantes nativos que hablan de encuentros (en su mayoría desagradables) con los espíritus de los muertos (los llamados ayakuna ${ }^{53}$ ). Estos individuos mantienen su intencionalidad volitiva activa incluso después de la muerte, pudiendo así volver sobre sus pasos e interferir en el mundo de los vivos, enfermándolos o incluso matando a infantes o animales ${ }^{54}$. El uso de

\footnotetext{
52 A través de sueños, visiones o encuentros reales con los espíritus.

53 Plural de aya.

54 Para una discusión más completa del tema, véase Volpi, 2021.
} 
la frase «volver sobre sus pasos» no es casual. Entre los kichwas se cree que un difunto solo puede transitar por los lugares conocidos en vida: su llakta, su chakra o los caminos visitados antes de su partida. Esta creencia es compartida por otras agrupaciones del Perú, que enfatizan que las almas de los muertos solo visitan los lugares a los que acudieron al menos una vez en su vida (Gow, 1991, p. 185).

Mientras me quedaba unos días en el pueblo de Huapo (a pocos kilómetros de la Comunidad Nativa Wayku), falleció una anciana que había conocido unos meses antes. A mi regreso, su hija me preguntó cómo pude dormir tranquila allá, sabiendo de su muerte, y aun así, decidiendo acampar tan cerca del bosque: su madre quizá me hubiera visitado por la noche, enfermándome o generando terribles pesadillas. Su marido, al oír la conversación, la corrigió inmediatamente: « ¡No digas tonterías! Tu madre nunca caminó por Huapo cuando estaba viva. Si Laura vio a alguien por la noche en el bosque, fue un demonio... ipero no tu madre! ${ }^{55}$.

La particular propensión de los fallecidos a andar solo por los lugares que conocieron en vida parece fundamental en el marco de la presente discusión. Uno de los objetivos de estas páginas es interpretar la ancestralidad indígena como una relación activa entre humanos, ex humanos y territorio. Este último, lejos de representar un área delimitada por fronteras jurídicas, es considerado como «una red de relaciones, un tejido en proceso de construcción y reconstrucción constante» (García Hierro y Surrallés, 2004, p. 21). En este espacio, la memoria nativa adquiere la apariencia de un producto tangible de la relación entre el hombre y el ambiente.

$\mathrm{Si}$, de hecho, en el llamado «modelo genealógico» los contenidos de la memoria (conocimiento ancestral, lengua nativa, antepasados) se consideran como datos objetivos, prexistentes al acto mismo de recordar, en el paradigma relacional (más cercano a la sensibilidad amazónica) emerge todo el peso creativo del recuerdo: los objetos de la memoria son generados en el presente y dependen del mismo acto mnemotécnico.

Entonces, caminar en el bosque y en la orilla del río con los nativos de San Martín, identificando elementos materiales que recuerden a sus ancestros, no significa simplemente «traer a la memoria los tatarabuelos». Cada elemento del entorno, indicado como significativo, constituye el nudo de una relación activa y presente con el propio pasado. Dicho con diferentes palabras, «el paisaje no solo evoca la memoria, sino [...] se convierte en memoria» (Santos-Granero, 2004, p. 203).

\footnotetext{
55 W.G., Wayku, 15 de mayo 2019.
} 


\section{CONCLUSIONES}

En la introducción a un importante volumen dedicado a las nociones de «tierra» y «territorio» (García Hierro y Surrallés, 2004), los editores preguntan provocativamente si es creíble afirmar que «con su título en mano, los pueblos y comunidades indígenas podrán [...] desenvolver sus visiones territoriales» (García Hierro y Surrallés, 2004, p. 9). La pregunta es, por supuesto, retórica. Como se ha demostrado a través de la presentación del caso de Nuevo Lamas de Shapaja, la atribución del título de propiedad a las Comunidades Nativas, a menudo ha sido insuficiente. El sospecho con lo cual, en el contexto analizado, numerosos líderes nativos consideran la titulación de tierras genera conflictos y malos humores entre las mismas federaciones indígenas, las autoridades locales y los mediadores culturales, que proponen proyectos orientados a facilitar el mismo proceso.

En estas páginas se ha sugerido la siguiente hipótesis: la incapacidad del gobierno estatal o regional para satisfacer plenamente las necesidades de las agrupaciones indígenas es el resultado de un gran malentendido sobre los conceptos de «ascendencia»y «territorio». Por un lado, las circunstancias políticas obligan a los líderes nativos y a los mediadores culturales a dialogar con los organismos estatales y regionales utilizando un discurso genealógico-estratégico, generado en el ámbito internacional de la protección de los derechos humanos y asimilado a través de un proceso de vernacularización. Simultáneamente, muchos individuos nativos siguen pensando sus propias reivindicaciones políticas mediante un concepto relacional del territorio.

Con la presentación de un caso etnográfico específico, además, ha sido posible observar cómo una familia nativa pudo reinterpretar creativamente el discurso genético-ancestral. Sus miembros (al sacar la narrativa biológica del paradigma genealógico) pueden, hoy en día, leerla a la luz de la singular forma indígena de concebir las relaciones humanas y territoriales. Esto permite demostrar cómo la idea de «ancestralidad» no puede ser descartada por los antropológos empeñados en el análisis de los conflictos politicos y territoriales como una mera trampa esencialista (Niezen, 2003). Por supuesto es difícil negar que, en algunos contextos políticos y culturales, los movimientos de defensa de los derechos indígenas conducen a una exacerbación de las «ficciones étnicas locales» (Kuper, 2003, p. 395). Sin embargo, las reflexiones presentadas en estas páginas resaltan cómo la esencialización de las identidades representa un problema solo para aquellos sectores políticos (indígenas y no indígenas) que persisten en promover 
una interpretación genealógico-occidental del discurso genético-ancestral ${ }^{56}$. Lo que se tiende a olvidar y a elidir, dentro de tal narrativa ${ }^{57}$, es la compleja red de relaciones (presentes y activas) que los actores locales tejen con los elementos del paisaje, con los objetos de la memoria y con sus antepasados. Estos últimos, actuálizandose en el ambiente e interactuando (en lugares específicos) con los seres humanos vivos, constituyen la verdadera esencia del nexo ancestral entre los nativos y su territorio.

\section{REFERENCIAS BIBLIOGRÁFICAS}

Aluli-Meyer, M. (2014) Indigenous Epistemology: Spirit Revealed, en. En T. Black (ed.), Enhancing Mātauranga Māori and Global Indigenous Knowledge (pp. 151-164). Wellington: NZQA.

Barbieri, C., Sandoval, J. S., Valqui, J., Shimelman, A., Ziemendorff, S., Schröder, R. y Geppert, M. (2017). Enclaves of genetic diversity resisted Inca impacts on population history. Scientific Reports, 7, 1-12. https://doi/org/10.1038/s41598017-17728-w.

Belaunde, Luisa Elvira (2008) El recuerdo de Luna: género, sangre y memoria entre los pueblos amazónicos. Lima: Fondo Editorial de la Facultad de Ciencias Sociales UNMSM.

Bettini, M. (2011). Contro le radici. Tradizione, identità e memoria. Bologna, Italia: Il Mulino.

Cachique Amasifuén, S. F. (2007). Diccionario kichwa-castellano/castellano-kichwa. Tarapoto, Peru: Aquinos.

Calderón Pacheco, L. (2003). Relaciones interétnicas entre mestizos y nativos kechwa en Lamas en el contexto de la globalización. En C. I. Degregori (ed.), Comunidades

56 Desde este punto de vista, parece importante subrayar que, en algunos contextos supranacionales, emerge hoy el concepto de territorio como un «espacio de relación activa» entre humanos y no humanos. Pensemos, por ejemplo, en la sentencia de la Corte Interamericana de Derechos Humanos de 31 de agosto de 2001, en la cual la propia idea de «territorio ancestral» es analizada a la luz del vínculo que los seres vivos entretejen con sus parientes enterrados en las tierras tradicionales, así como con otros elementos sobrenaturales. El territorio ancestral, en este documento, es concebido como tal porque no solo ofrece «refugio a los miembros vivos de la comunidad, sino también a los restos mortales de sus antepasados, así como a las deidades» (Corte Interamericana de Derechos Humanos, sentencia del 31 de agosto de 2001). Para más reflexiones sobre el interés del derecho internacional por esta concepción relacional del medio ambiente, véase también Surrallés, 2017.

57 Propuestos tanto por los entes regionales y estadales como por los líderes nativos, los funcionarios de las ONG y los abogados de derechos indígenas. 
locales y transnacionales (pp. 13-104). Lima, Perú: Instituto de Estudios Peruanos.

Cavalli-Sforza, L. L. (1996). Geni, popoli e lingue. Milano: Adelphi.

Chaumeil, J. P. (2010). Historia de Lince, de Inca y de Blanco. La percepción del cambio en las tradiciones amerindias. Maguaré. Miradas lejanas, 59-67. https:// doi.org/10.15446/mag.v0n24\%20N.Esp..17879

Deleuze, G., Guattari, F. (1988). A thousand plateaus: capitalism and schizophrenia. London: Athlone.

Descola, P. (1992). Society of nature, and the nature of society. En A. Kuper (ed.), Conceptualiziting Society (pp. 107-126). Londres: Routledge.

Descola, P. (1997). Las cosmologías de los indios de la Amazonia. Mundo Cientifico, $175,60-65$.

Descola, P. (2005). Par-delà nature et culture. París: Gallimard.

Doerty, J. (2007). Richak-laya Rimana Tarina. Diccionario del quechua de San Martín. Lamas: Academia Regional de Kechwa.

Faustos C. (2002). Banquete de gente: comensalidade e canibalismo na Amazônia. Mana, 8(2),7-44.

Favre, H. (2005). El movimiento indianista: un fenómeno «glocal». IVème Congrès National d'Anthropologie, Lima.

FECONAU,CEPKA(2018). Shadowreport. Recuperadodehttp://www.forestpeoples.org/ sites/default/files/documents/CERD_Peru_ShadowReport_95_29thMarch2018

Figueroa, F. (1986). Informe de jesuitas en el Amazonas: 1660-1684. Iquitos: Monumenta Amazónica CETA.

García Hierro, P.; Surrallés, A. (2004). Introducción. En P. García Hierro y A. Surrallés (eds.), Tierra adentro. Territorio indígena y percepción del entorno (pp. 9-22). Lima: IWIGA.

Gow, P. (1991). Of Mixed Blood: Kinship and History in Peruvian Amazonia. Oxford: Clarendon Press.

Ingold, T. (2000) The Perception of the Environment: Essays on Livelihood, Dwelling and Skill. Londres: Routledge.

Kent, M. (2013). The Importance of Being Uros: Indigenous Identity Politics in the Genomic Age. Social Studies of Science, 43(4), 534-556. https://doi. org/10.1177/0306312712468520.

Kent, M., Santos, R. V. (2012). Os charruas «vivem» nos Gaúchos: a vida social de uma pesquisa de «resgate» genético de uma etnia indígena extinta no Sul do Brasil. 
Horizontes Antropológicos, 18(37), 341-372. https://doi.org/10.1590/S010471832012000100015 .

Kuper, A. (2003). The Return of the Native. Current Anthropology, 44(3), 389-402. https://doi.org/10.1086/368120.

Marry, S. E. (2006). Transnational Human Rights and Local Activism: Mapping the Middle. American Anthropologist, 108(1), 38-51. https://doi.org/10.1525/ aa.2006.108.1.38.

Martínez Cobo, J. (1982). Study of the Problem of Discrimination Against Indigenous Populations: Final report submitted by the Special Rapporteur. Recuperado de https://www.un.org/development/desa/indigenouspeoples/publications/martinez-cobo-study.html.

Mouriès, T. (2014). ¿Con o sin ancestros? Vigencia de lo ancestral en la Amazonía peruana. Anthropologica del Departamento de Ciencias Sociales, 32(32), 17-40. Recuperado de http://revistas.pucp.edu.pe/index.php/anthropologica/article/ view/9442.

Niezen, R. (2003). The origins of indigenism. Human Rights and the Politics of Identity. Berkeley y Los Angeles: University of California Press.

Palmié, S. (2007). Genomics, Divination, «Racecraft». American Ethnologist, 34(2), 205-222. Recuperado de http://www.jstor.org/stable/4496796.

Rival, L (2004). El crecimiento de las familias y de los árboles: la percepción del bosque de los huaorani. En P. García Hierro y A. Surrallés (eds.), Tierra adentro. Territorio indígena y percepción del entorno (pp. 97-121). Lima: IWIGA.

Rabinow, P. (2010). Artificiality and Enlightenment: From sociobiology to biosociality. Politix, 90(2), 21-46. https://doi.org/10.3917/pox.090.0021.

Sandoval J. R., Lacerda, D. R., Acosta, O., Jota, M. S., Robles-Ruiz, P., Salazar-Granara, A., Vieira P. P., Paz-y-Miño, C., Fujita, R., Santos, F. R. (2016). The Genetic History of Peruvian Quechua-Lamistas and Chankas: Uniparental DNA Patterns among Autochthonous Amazonian and Andean Populations. Ann Hum Genet., 80(2), 88-101. https://doi.org/ 10.1111/ahg.12145. Epub 2016 Feb 16. PMID: 26879156; PMCID: PMC5111738.

Santos-Granero, F. (2004). Escribiendo la historia en el paisaje: espacio, mitología y ritual entre la gente yanesha. En P. García Hierro y A. Surrallés (eds.), Tierra adentro. Territorio indígena y percepción del entorno (pp. 187-220). Lima: IWIGA.

Sapignoli, M. (2018). Hunting Justice: Displacement, Law, and Activism in the Kalahari. Cambridge: Cambridge University Press. 
Scazzocchio, F. (1979) Ethnicity and boundary maintenance among peruvian forest quechua. Tesis de doctorado. Cambrige University.

SERNANP (2013). Documento de trabajo 5. Áreas de Conservación Regional. Recuperado de https://www.sernanp.gob.pe/documents/10181/147284/5+Doc+Tra bajo + Areas + de + Conservacion + Regional $+(1) . p d f / e a 712 f c 6-7 e 14-459 c-b 281$ $06007 \mathrm{aa} 7 \mathrm{aa} 02$.

Simpson, R. (2000). Imagined Genetic Communities: Ethnicity and Essentialism in the Twenty-First Century. Anthropology Today, 16(3), 3-6. https://doi. org/10.1111/1467-8322.00023.

Solinas, P. G. (2015). Ancestry. Parentele elettroniche e lignaggi genetici. Firenze: Editpress.

Surrallés, A. (2009). Entre derecho y realidad: antropología y territorios indígenas amazónicos en un futuro próximo. Bulletin de l'Institut français d'études andines, 38(1), 29-45. https://doi.org/10.4000/bifea.2789.

Surrallés, A. (2017). Human rights for nonhumans? Hau: Journal of Ethnographic Theory, 7(3), 211-235.

Tamarkin, N. (2014). Genetic Diaspora: Producing Knowledge of Genes and Jews in Rural South Africa. Cultural Anthropology, 29(3), 552-74. https://doi. org/10.14506/ca29.3.06.

Trupiano, V. (2013). Gli usi della diversità genetica. DNA, parentele e politiche dell'appartenenza. Bologna: Il Mulino.

Viveiros de Castro, E. (1992) From the enemy's point of view: humanity and divinity in an Amazonian society. Chicago/Londres: The University of Chicago Press.

Weiss, P. (1949). Estudio sobre los lamistas, su grupo sanguíneo, algunas pruebas psicotécnicas. Sobretiro de la Revista del Museo Nacional, 18, 1-24.

Zerubavel, E. (2004). Time Maps: Collective Memory and the Social Shape of the Past. Chicago: University of Chicago Press. 